\title{
Intestinal growth-promoting properties of glucagon-like peptide-2 in mice
}

\author{
CHUN-HUI TSAI, ${ }^{1}$ MARY HILL, ${ }^{1}$ SYLVIA L. ASA, ${ }^{2}$ \\ PATRICIA L. BRUBAKER, ${ }^{1,3}$ AND DANIEL J. DRUCKER ${ }^{1}$ \\ Departments of ${ }^{1}$ Medicine, ${ }^{2}$ Pathology, and ${ }^{3}$ Physiology, Banting and Best Diabetes Centre, \\ The Toronto Hospital, University of Toronto, Toronto, Ontario, Canada M5G 2C4
}

\begin{abstract}
Tsai, Chun-Hui, Mary Hill, Sylvia L. Asa, Patricia L. Brubaker, and Daniel J. Drucker. Intestinal growthpromoting properties of glucagon-like peptide-2 in mice. Am. J. Physiol. 273 (Endocrinol. Metab. 36): E77-E84, 1997.Glucagon-like peptide-2 (GLP-2) has been shown to promote intestinal epithelial proliferation. We studied crypt cell proliferation, enterocyte cell death, and feeding behavior in GLP-2treated mice. GLP-2 had no effect on food consumption [7.7 \pm 0.3 vs. $8.0 \pm 0.4 \mathrm{~g} /$ day, saline (control) vs. GLP-2-treated mice, $P=$ not significant]; however, GLP-2 increased the crypt cell proliferation rate $(46.0 \pm 1$ vs. $57 \pm 5 \%$, control vs. GLP-2, $P<0.01)$ and decreased the enterocyte apoptotic rate $(5.9 \pm$ 0.7 vs. $2.8 \pm 0.2 \%$ apoptotic cells, control vs. GLP- $2, P<0.05$ ) in small bowel (SB) epithelium. GLP-2 induced a significant increase in SB weight (1.3- to 1.75-fold increase over control, $P<0.05$ to $P<0.001)$ in mice $1-24$ mo of age. Increased SB weight was maintained after daily administration of GLP-2 to mice for $12 \mathrm{wk}$, and cessation of GLP-2 administration in older mice led to regression of (increased) SB weight and mucosal height. These observations suggest that GLP-2 regulates both cell proliferation and apoptosis and promotes intestinal growth after both short- and long-term administration in vivo.
\end{abstract}

bowel; growth factor; apoptosis; feeding

THE SPECIALIZED EPITHELIAL cells of the small intestine constitute a functionally important organ for nutrient absorption, immune function, and regulation of fluid and electrolyte balance. Diseases that disrupt the integrity of the small bowel epithelium, either through inflammation, infiltration, surgical resection, or ischemia, may result in malabsorption leading to clinically significant nutritional impairment requiring parenteral nutritional support. The number of patients requiring parenteral support appears to be increasing (14); however, alternative strategies directed at restitution and regrowth of functional small bowel cpithelium, although under study and development (2), have not yet been widely implemented.

The normal adaptive response to small bowel resection strongly suggests that the small intestinal epithelium retains the capacity for regrowth and selfrenewal. A number of nutritional and hormonal factors appear to be important for control of small bowel growth in vivo. Experiments utilizing transgenic mice have demonstrated that overexpression of growth hormone and the insulin-like growth factors (IGFs) is associated with both small and large bowel growth (1, 29,31 ), and administration of IGF-I and its analogs to rats leads to increased growth of the stomach, small bowel, and colon (16). Growth factors such as epidermal growth factor (EGF)/urogastrone and transforming growth factor- $\alpha$ (TGF- $\alpha$ ), which are synthesized locally by intestinal epithelial cells, also stimulate intestinal cell growth both in vitro and in vivo (19). Peptide hormones produced in enteroendocrine cells have also been implicated in the regulation of small bowel growth, as administration of bombesin and neurotensin induces small bowel epithelial proliferation in rodent models (26).

Peptides derived from posttranslational processing of proglucagon (PGDPs) have previously been implicated as putative mediators of the adaptive response to small bowel injury and resection. Two patients with glucagon-producing tumors were found to have villus enlargement of the small bowel (11, 25); the small bowel abnormalities regressed after tumor resection, suggesting a possible link between excess PGDP production and bowel growth. Circulating levels of PGDPs increase in human subjects with intestinal diseases associated with small bowel adaptation and after intestinal resection, and proglucagon mRNA transcripts are increased in the remnant intestine after major small bowel resection in the rat $(10,27)$. Nevertheless, attempts at identifying a specific PGDP responsible for bowel growth by immunoneutralization of enteroglucagon did not result in modification of the adaptive response to intestinal resection in rats (13).

We recently identified glucagon-like peptide (GLP)-2 as the PGDP with intestinal growth-enhancing activity by demonstrating that short-term (10 days) administration of synthetic rat GLP-2 (but not other PGDPs such as GLP-1 or intervening peptide-2) to 6-wk-old CD1 female mice was associated with induction of small bowel growth (7). To explore the potential efficacy of GLP-2 as a small bowel growth factor, we carried out studies examining the response of the intestine to both short- and long-term GLP-2 administration in young and aged male and female mice.

\section{METHODS}

All chemicals were from Sigma Chemical (St.Louis, MO) or Baxter Travenol Canada (Toronto, ON, Canada). Immunohistochemical reagents were obtained from Boehringer Mannheim Canada (Toronto, ON, Canada), Dimension Laboratories (Toronto, ON, Canada), or Dakopatts (Glostrup, Denmark). Rat GLP-2 was obtained from American Peptide (Sunnyvale, CA) or from California Peptide Research (Napa, CA).

Mice. CD1 mice were obtained from Charles River Laboratory (St. Constant, PQ, Canada). The CD1 mice were agematched males or females ( $n=3-4$ mice/group) from 4 to 16 wk of age. The animals were allowed a minimum of $24 \mathrm{~h}$ (but usually 3-6 days) to acclimatize to the laboratory facility before the initiation of each experiment. Older mice, from 6 to 24 mo of age, were C57BL/6 animals from the National 
Institute on Aging rodent colony maintained at Charles River Laboratories (Kingston, NY). Mice were not restricted by diet or activity during the expcriment and were housed 3-4 per cage under a light-dark cycle of $12 \mathrm{~h}$. Animals were fasted overnight (12-14 h) before being killed, usually 14 days after the initiation of GLP-2 administration, unless otherwise specified.

Animal and tissue processing. Mice were anesthetized with $\mathrm{CO}_{2}$, and the small and large intestines were removed from the peritoneal cavity (from pylorus to cecum), cleaned, weighed, and measured. For comparative purpose, sections from each animal were obtained from the identical anatomic position. Fragments measuring $1.5-2.0 \mathrm{~cm}$ in length were obtained $8 \pm 2 \mathrm{~cm}, 18 \pm 2 \mathrm{~cm}$, and $32 \pm 2 \mathrm{~cm}$ from the pylorus for histomorphometry, representing proximal jejunum, distal jejunum, and distal ileum, respectively. Each small bowel fragment was opened longitudinally on its antimesenteric border, sectioned, and then placed in $10 \%$ Formalin (vol/vol) overnight.

Intestinal micrometry. Five-micrometer-thick sections were cut, stained with hematoxylin and cosin, and uscd for micrometry and morphometric analysis. Intestinal micrometry was performed with the use of a Leitz (Wetzar, Germany) microscope with a video camera connected to a computer monitor. The microscope was calibrated at $\times 4, \times 10$, and $\times 25$ magnification, and the same microscope was used for all evaluations. Crypt-plus-villus height was measured by examining at least 20 longitudinally oriented villi from each slide for proximal and distal jejunum and distal ileum and is expressed in micrometers $( \pm \mathrm{SE})$. The width of the muscularis layer was similarly determined and is expressed in micrometers (mean $\pm \mathrm{SE}$ ).

Immunocytochemistry. Separate 3 - to $5-\mathrm{mm}$ sections of small intestine were cut for immunostaining for proliferating cell nuclear antigen (PCNA) and for apoptosis analysis. Results for PCNA and bromodeoxyuridine (Br-dU) are expressed as the percentage of positive-staining crypt cells or the number of $\mathrm{Br}$-dU-positive cells per villus. PCNA immunochemistry utilized a primary antibody (Novocastra, Newcastleupon-Tyne, UK) at 1:1,500 after microwave antigen retrieval. $\mathrm{Br}$-dU staining was carried out as previously described (7). A minimum of 15 to a maximum of 30 longitudinally oriented crypt/villus axes were counted per section per animal. Apoptotic bodies were identified by the TdT-mediated dUTP nick end labeling (TUNEL) immunologic method with the use of the Apoptag Plus in situ detection kit (Oncor, Gaithersburg, MD). The percentage of apoptotic, TUNEL-immunopositive enterocytes was determined per each $1,000 \times$ field. Final results are plotted as means \pm SE for GLP-2-treated and phosphate-buffered saline (PBS)-treated (control) mice.

Food intake studies. Feeding experiments were carried out in 6-wk-old female CD1 mice that had been acclimatized to the animal facility for $1 \mathrm{wk}$. Mice were weighed, transferred to a clean cage, and given a preweighed amount of powdered food (Purina Rodent Chow) in a small plastic beaker immobilized in the center of a $10-\mathrm{cm}$ petri dish (to catch scattered food). Mice were injected with GLP-2 (2.5 $\mu \mathrm{g}$ every $12 \mathrm{~h})$ or vehicle for 10 days ( $n=5$ mice/group). Food intake and body weight were determined at 5 PM daily until day 9 , whereupon food was removed and mice were fasted overnight before being killed.

Intestinal wet and dry weight and protein content. Two (2-cm) segments from the proximal jejunum, ileum, and colon were removed, placed in separate preweighed culture tubes, and reweighed. The tubes were covered with parafilm (with pinholes), placed upright in a 1,200-ml Fast-Freeze flask (Labconco), and freeze-dried overnight. The tubes and dried, room temperature contents were reweighed, and dry weight per 2-cm segment was calculated. For protein content, two 2 -cm segments from the proximal jejunum, ileum, and colon were removed and placed in 13-ml tubes containing $2 \mathrm{ml}$ PBS. Each segment was homogenized for $20 \mathrm{~s}$ with the use of a Brinkmann Homogenizer and placed on ice. The tubes were centrifuged $(1,000 \mathrm{~g})$ for $5 \mathrm{~min}$, and 100- $\mu \mathrm{l}$ aliquots of the supernatant homogenate were removed for determination of protein content with the use of the modified Bradford method. The locations of the intestinal segments used for various analyses are as follows. For the proximal jejunum, the first 8 $\mathrm{cm}$ were used for microscopy, the next $2 \mathrm{~cm}$ for protein, the next $2 \mathrm{~cm}$ for weights, the next $2 \mathrm{~cm}$ for protein, and the next $2 \mathrm{~cm}$ for weights. For the ileum, starting $10 \mathrm{~cm}$ proximal to the cecum, a similar pattern of alternating $2-\mathrm{cm}$ segments was obtained for protein and weight analyses, and for the colon, the alternating $2-\mathrm{cm}$ segments for protein and weight were obtained beginning just distal to the cecum.

Statistical analysis. Statistical significance was calculated by analysis of variance with the use of a SAS program (Statistical Analysis Systems, Cary, NC) for IBM computers.

\section{RESULTS}

Administration of GLP-2 subcutaneously (every $12 \mathrm{~h}$ ) to 6- to 8-wk-old female CD1 mice at concentrations ranging from 43.75 to $6.25 \mu \mathrm{g} /$ injection for 10 days resulted in increased small bowel weight (1.5-2-fold, $P<0.01)$ and villus height $(1.2-1.5$-fold, $P<0.001)(7)$. To determine if the small bowel response to GLP-2 was restricted to young female mice, we administered GLP-2 $(2.5 \mu \mathrm{g}$ twice a day) or PBS to male and female mice 4-16 wk of age for 14 days. The results of this experiment (Fig. 1, $A$ and $B$ ) demonstrated that GLP-2 treatment was associated with a statistically significant increase in small bowel weight in both younger and older male and female CD1 mice $(P<0.05-0.001)$. GLP-2 administration was also associated with an increase in small bowel mucosal crypt-plus-villus height (Fig. 1, $A$ and $B, P<0.05-0.001$ ). The increased mucosal height was generally greater in the jejunum than in the ileum and was primarily attributable to an increase in villus height, as the values for crypt depth were consistently comparable in control and GLP-2treated animals (data not shown).

Because the determinants of villus epithelial proliferation and the response of the small bowel to the growth factor-like properties of GLP-2 may differ in older compared with younger animals, we assessed the effect of GLP-2 on the small intestine of female C57BL/6 mice 6-24 mo of age. GLP-2 administration, $2.5 \mu \mathrm{g}$ twice a day, to older mice for 14 days consistently increased both small bowel weight (1.35- to 1.6-fold increase compared with PBS-treated controls, $P<$ 0.05-0.01; Fig. 2A) and crypt-plus-villus height in both jejunum $(P<0.05-0.01$, Fig. $2 B)$ and ileum (data not shown).

To determine whether the GLP-2-induced increase in small bowel epithelium regresses after cessation of GLP-2 administration, a second group of age-matched GLP-2-treated C57BL/6 mice was treated for 14 days, after which GLP-2 (or PBS) injections were stopped and the animals were killed for histological analysis 10 days later. In contrast to the increased small bowel 
A


B
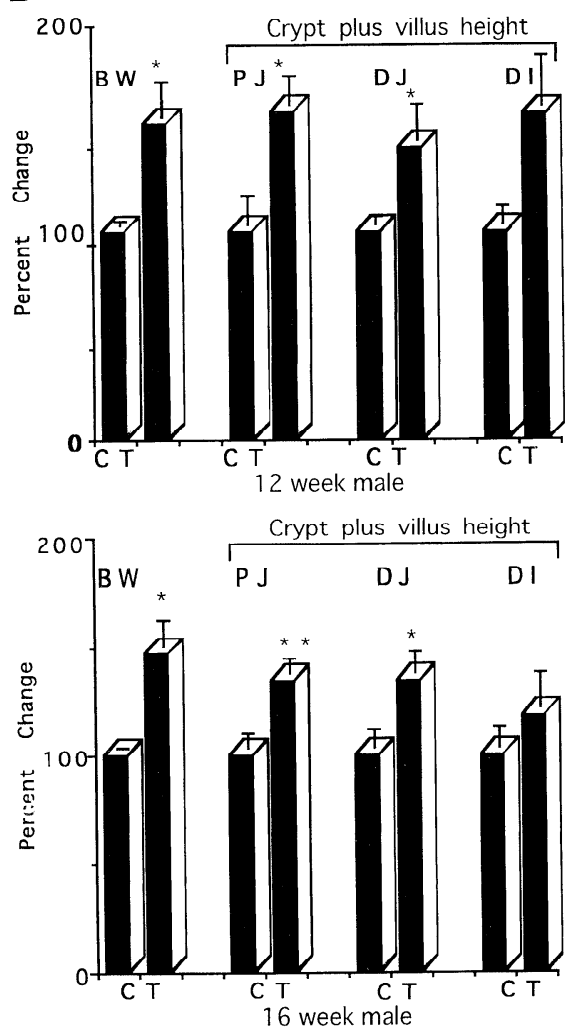
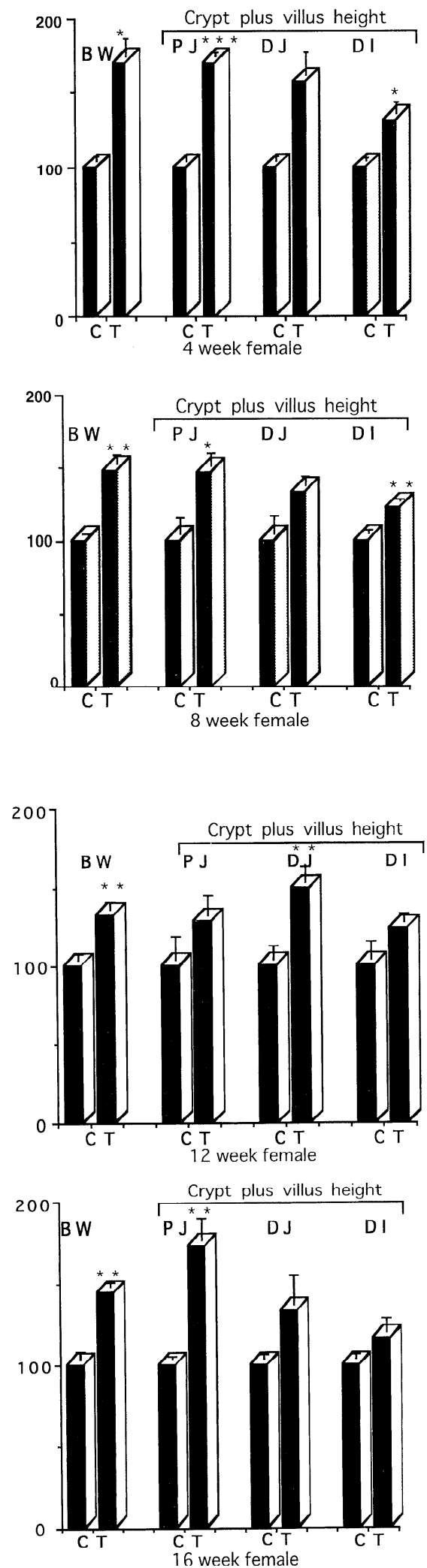

Fig. 1. $A$ and $B$ : efficacy of glucagon-like peptide (GLP)-2 administration in male and female mice. Malc and femalc CD1 mice ( $n-4$ mice/group) 4-16 wk of age were treated with phosphatebuffered saline (PBS) [control (C)] or GLP-2 [treatment group (T), $2.5 \mu \mathrm{g}$ twice a day] for 14 days. Mice were injected sc with $0.5 \mathrm{ml}$ of PBS alone or with peptide every $12 \mathrm{~h}$. After 14 days, mice were killed by $\mathrm{CO}_{2}$ anesthesia and bowel weight and histolngy were assessed as described in METHODS. Data represent \%change (mean \pm SE, GLP-2treated group compared with PBS-treated group) for bowel weight (BW) and crypt-plus-villus height. PJ, proximal jejunum; DJ, distal jejunum; DI, distal ileum. Statistically significant difference compared with control: $* P<0.05$, $* * P<$ $0.01,{ }^{* * *} P<0.001$. weights observed in GLP-2-treated mice after 14 days, 10 days after cessation of peptide administration, the small bowel weights of the GLP-2- and PBS-treated mice were highly similar in mice 6,12 , and 18 mo of age (Fig. 2A). The small bowel weights of 24-mo-old GLP-2treated mice also regressed toward control values; however, a small but statistically significant increase in small bowel weight was still detectable 10 days after the last injection in 24-mo-old GLP-2-treated mice (Fig. $2 A$ ). Histologically detectable increases in jejunal cryptplus-villus height were also observed in the 18- and 24-mo-old mice after cessation of GLP-2 administra- 


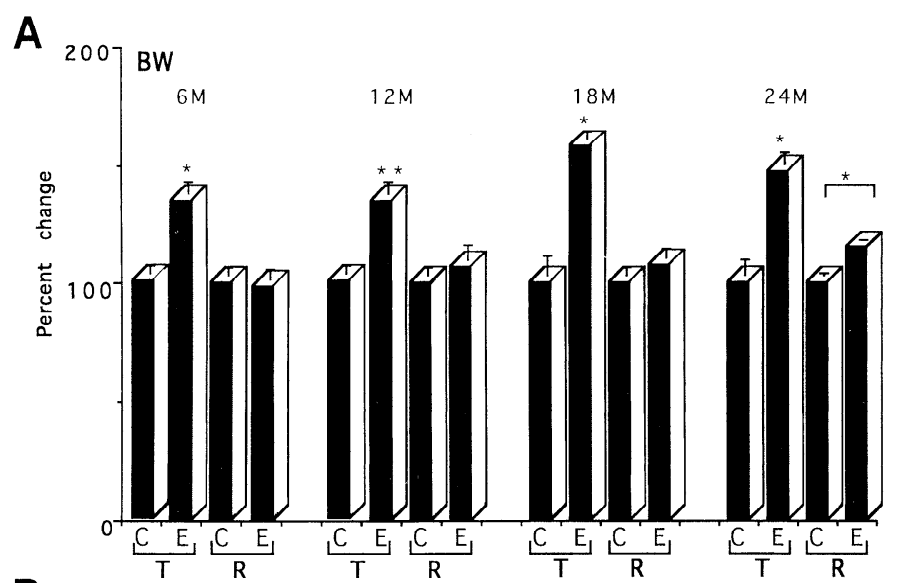

B

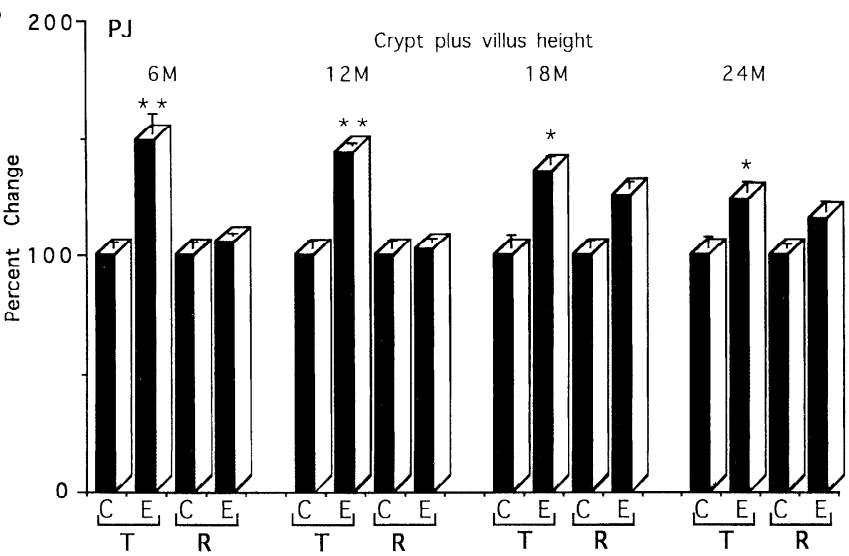

Fig. 2. GLP-2 induces small bowel growth in older mice. Four groups $(n=4)$ of female C57BLK mice $6-24$ mo $(6 \mathrm{M}-24 \mathrm{M})$ of age were treated with PBS (C) or GIP-2 [experimental (E), $1.95 \mu \mathrm{g}$ sc twice a day] for 14 days, after which 2 groups (both PBS and GLP-2 treated) were killed for analysis (T). Remaining mice [regression group (R)] were allowed continued access to unlimited food and water for an additional 10 days (but without PBS or GLP-2 injections) and then killed for analysis of small bowel weight (BW; $A$ ) and histomorphomctry, or proximal jejunum (PJ) crypt-plus-villus height $(B)$. $* P<0.05$, *** $P<0.01$.

tion, although these differences were not statistically significant (Fig. $2 B$ ). These data demonstrate that the increased villus height and small bowel weight that develop as a consequence of GLP-2 treatment are reversible after GLP-2 withdrawal; however, the degree or kinetics of reversal may be delayed in older animals, consistent with the possible differences in epithelial turnover in older animals (reviewed in Ref. 8 ). The results of the experiments described above demonstrate that GLP-2, administered twice daily for 14 days, exhibits small bowel growth factor activity in both young and aged mice; however, the small bowel epithelial proliferation appears to be dependent on ongoing GLP-2 administration.

'To determine whether long-term GLP-2 administration results in downregulation of the GLP-2 receptor system and reduction of GLP-2 bioactivity in the small bowel, we administered GLP-2 (in a single daily injection) to groups of mice for 4,8 , and 12 wk (Fig. 3). Analysis of mice after 4, 8, and 12 wk of daily GLP-2 (vs. PBS) injections demonstrated increased small bowel weight and villus height in the GLP-2-treated animals.
The increase in small intestinal weight was statistically significant in mice treated for 8 and $12 \mathrm{wk}$ $(P<0.05-0.001$, Fig. 3$)$. The increase in villus height was also statistically significant $(P<0.05-0.01)$ and more prominent in the jejunum than in the ileum (Fig. 3).

Because enteral nutrient ingestion is known to be associated with increased adaptation of the small bowel (12), the observation that GLP-1 modifies food intake in rodents (28) prompted us to assess whether the effect of GLP-2 on small bowel growth was mediated in part by effects on food intake. Accordingly, daily food intake and body weight were assessed in paired groups of rodents given unlimited access to rodent chow, with either GLP-2 or PBS administered twice daily. The results of these experiments (Fig. 4) demonstrated that GLP-2 treatment had no effect on food intake or body weight, suggesting that GLP-2 docs not stimulate intestinal proliferation via an effect on food consumption.

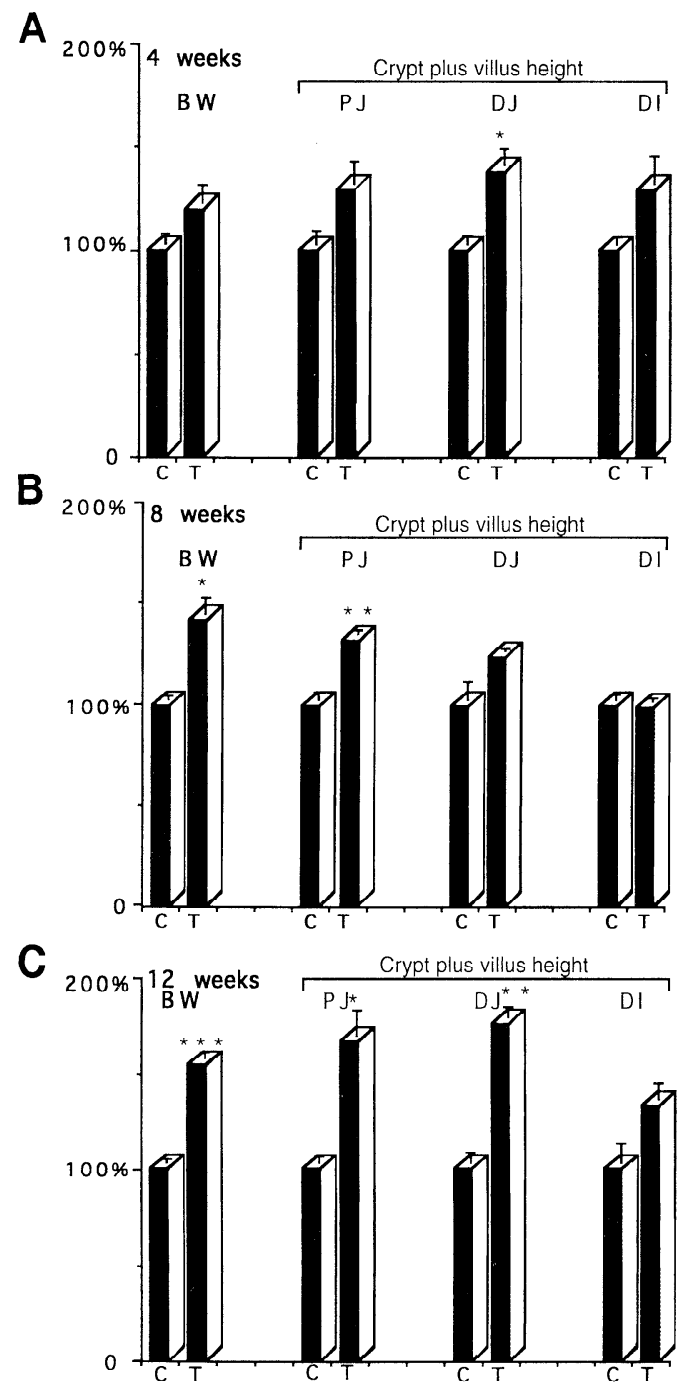

Fig. 3. Fffect of daily administration (4-12 wk) of GLP-2 on small bowel of CD1 mice. GLP-2 (T) or PBS (C) was administered (3.9 $\mu \mathrm{g} \mathrm{sc}$ each day) to groups $(n=4)$ of female CD1 mice $(6 \mathrm{wk}$ of age at intiation of each experiment) for 4,8 , or $12 \mathrm{wk}$. Data represent \%change in small bowel weight (BW) or crypt-plus-villus height for GLP-2-treated vs. control mice. ${ }^{*} P<0.05$, ${ }^{* *} P<0.01$, ${ }^{* * *} P<0.001$. 

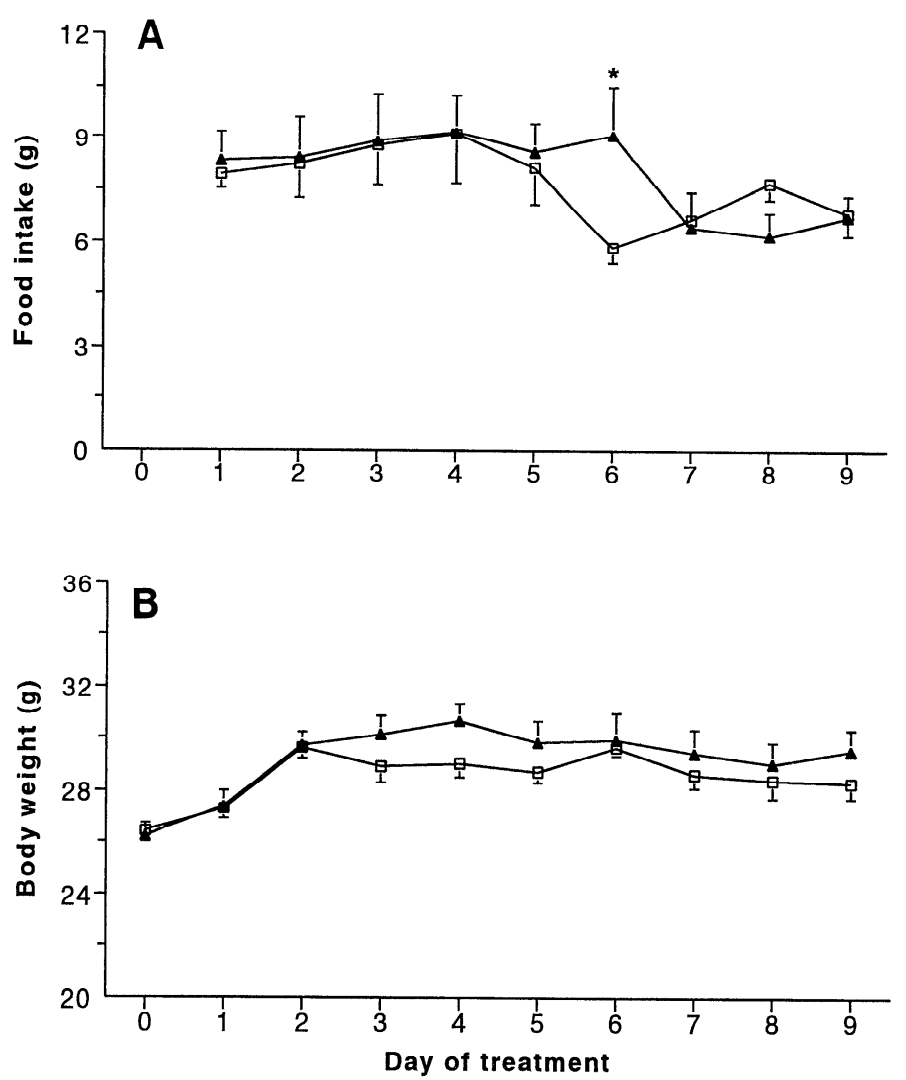

Fig. 4. Effect of GLP-2 on feeding in CD1 mice. Daily food consumption $(A)$ and body weight $(B)$ of mice treated with PBS $(\square)$ or $2.5 \mu \mathrm{g}$ rat GLP-2 (ム) sc twice a day for 9 days. $* P<0.05$.

The small intestine of mice carrying PGDP-producing tumors or mice injected with GLP-2 contains an increased number of proliferating cells in the crypts (7). To assess changes in crypt cell proliferation after GLP-2 administration, 6-wk-old female CD1 mice were treated with GLP-2, $2.5 \mu \mathrm{g}$ twice daily for 10 days, after which jejunal crypt cell proliferation rates were assessed as previously described (7). GLP-2 treatment was associated with a statistically significant increase in the crypt cell proliferation rate $(46.0 \pm 1$ vs. $57 \pm 5 \%$, control vs. GLP-2, $P<0.01$; Fig. $5 A$ ). The increase in villus epithelium after GLP-2 treatment may also be accounted for in part by an inhibitory effect of GLP-2 on enterocyte programmed cell death. To determine whether the small bowel epithelium of GLP-2-treated mice exhibited a decreased number of apoptotic cells, apoptotic rates were assessed in enterocytes of mice treated with PBS or GLP-2, $2.5 \mu \mathrm{g}$ twice daily for 10 days (Fig. $5 B$ ). The number of apoptotic cells in the villi (expressed as percent immunopositive apoptotic enterocytes) was $5.85 \pm 0.73$ in control mice and was reduced to $2.76 \pm 0.21$ in the GLP-2-treated mice $(P<0.05)$. The distribution of apoptotic cells was similar in control and GLP-2-treated mice; they were found at the tips of the villi and occasionally along the sides, but not at the base of the villi or in the crypts.

To ascertain the proliferative response to a single injection of GLP-2, paired groups of mice were injected with saline or $5 \mu \mathrm{g}$ GLP-2 and killed 2-72 $\mathrm{h}$ after injection. The jejunal crypt cell proliferation rate $2 \mathrm{~h}$ after injection was $30.1 \pm 1.4$ vs. $42.0 \pm 2.4 \%$ in saline vs. GLP-2-treated mice, respectively, $P<0.0001$. No significant differences in crypt cell proliferation rates were detected after analysis of Br-dU-labeled cells 12-36 h after GLP-2 or saline administration; however, at $48 \mathrm{~h}, 3.2 \pm 0.7 \%$ of crypt cells were labeled in GLP-2-treated mice, but no labeling of crypt cells was detected in control mice. These observations suggest that a single injection of GLP-2 is sufficient for the promotion of crypt cell division in vivo.

The results presented above demonstrate that an increase in the mucosal epithelium, predominantly villus height, is a consistent finding after GLP-2 administration. To ascertain whether changes in the thickness of the muscularis layer of the small bowel could be detected after GLP-2 treatment, multiple histological sections from the 4- and 8-wk-old groups of salinetreated control or GLP-2-treated mice (Fig. 1A) were cxamined for quantitative assessment of the muscularis layer (Fig. 6). No significant change in muscle thickness (longitudinal plus circular muscle) was observed in control vs. GLP-2-treated mice (Fig. 6A). The mean length of the small bowel was 45.7 vs. $50.7 \mathrm{~cm}$ in saline vs. GLP-2-treated mice, respectively $(P<0.05)$. To determine the relative contribution of water to the
A

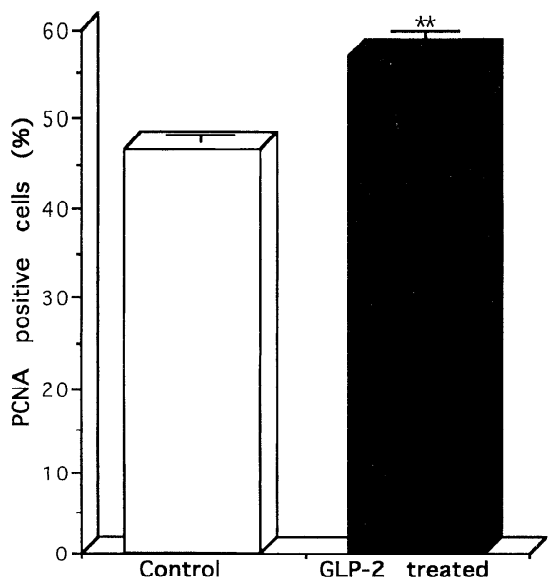

B

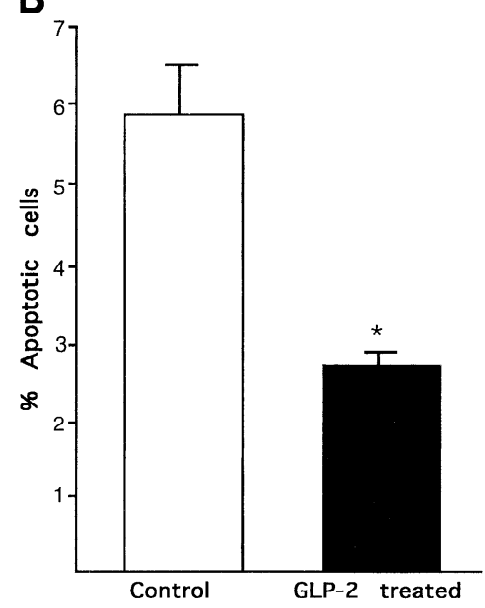

Fig. 5. A: crypt cell proliferation rates in jejunum of GLP-2-treated (2.5 $\mu \mathrm{g}$ twice daily for 10 days) and control mice. Sections were immunostained by proliferating cell nuclear antigen (PCNA), and results are means \pm SE. ${ }^{* *} P<0.01$. B: apoptotic cell numbers in GLP-2-treated vs. control (PBS-treated) mice. Sections from jejunum were immunostained by avidin-conjugated antidigoxigenin peroxidase. Percent apoptotic cells were assessed as total number of immunopositive cells divided by total number of intestinal epithelial cells per high power field. Results are means \pm SE for groups of GLP-2-treated and control animals. $* P<0.05$. 
A

Fig. 6. A: thickness of muscularis layer (longitudinal and circular muscle) was assessed by quantitative histomorphometry in histological sections from 4- and 8-wkold female CD1 mice (see Fig. 1) for proximal and distal jejunum (PJ and DJ, respectively) and distal ileum (DI). Data are expressed in $\mu \mathrm{m}$ as means \pm SE. $B$ : female CD1 mice (6 wk old) were treated with rat GLP-2, $2.5 \mu \mathrm{g}$ twice daily sc for 10 days, after which segments of proximal jejunum, ileum (I), and colon (C) were obtained for analysis of protein concentration (means \pm $\mathrm{SE}$ in $\mathrm{mg} / 2$-cm segment) as outlined in METHODS. ${ }^{*} P<$ 0.05. $C$ : wet and dry weight (expressed as means $\pm \mathrm{SE}$ in $\mathrm{mg} / 2$-cm segment) from proximal jejunum, ileum, and colon in CD1 mice treated with GLP-2 as described in $B$. ** $P<0.01$. For $A, B$, and $C$ : open bars, control; solid bars, GLP-2-treated mice.
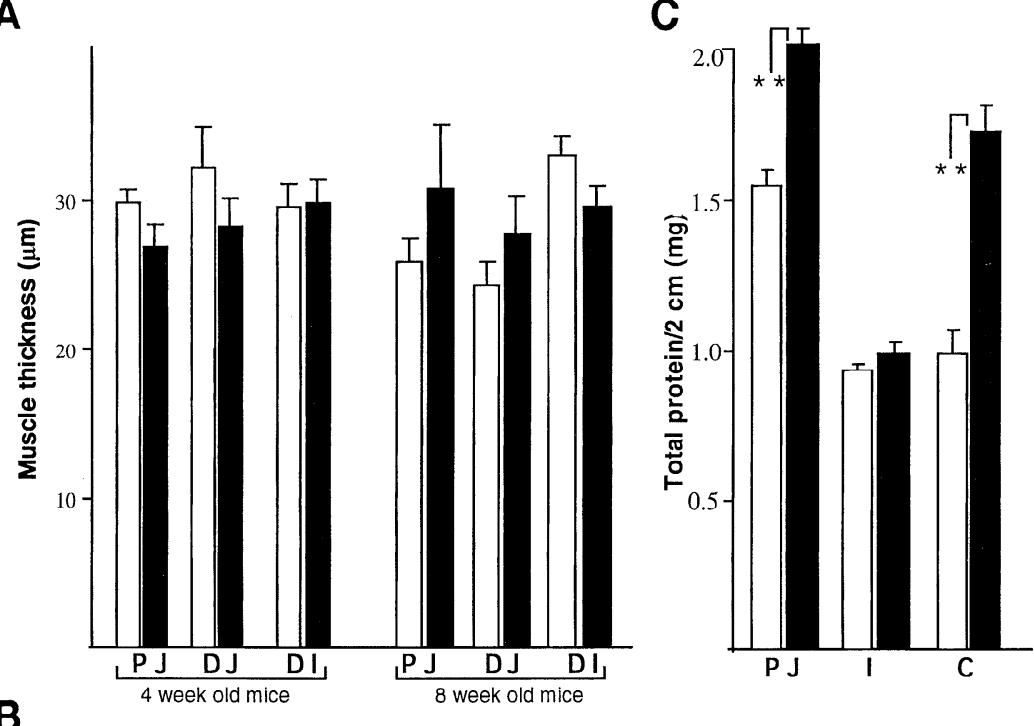

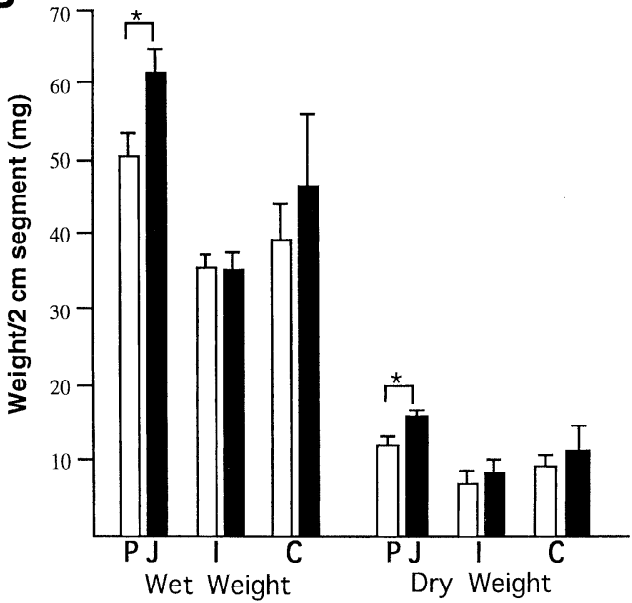

increment in small bowel weight observed after GLP-2 treatment, segments of proximal jejunum, ileum, and colon were weighed, desiccated, and reweighed (Fig. $6 B$ ). Both the wet and dry weights of intestinal segments from the proximal jejunum were significantly increased after treatment with GLP-2 $(P<0.05)$. Although the weights of the segments obtained from the colon were slightly increased after GLP-2, these differences were not statistically significant. In contrast, a statistically significant increase in protein content was observed in both the jejunum and colon of GLP-2-treated mice in the same experiments $(P<0.01$, Fig. $6 C)$.

\section{DISCUSSION}

GLP-2 is produced throughout the intestine in enteroendocrine cells of both the small and large bowel, with the highest concentration of intestinal $\mathrm{L}$ cells located in the distal ileum. The distribution of enteroendocrine cells in close proximity to both crypt cells and enterocytes raise the possibility that GLP-2 acts locally in a paracrine manner to modulate small bowel epithelial proliferation. Nevertheless, GLP-2 is clearly effective as a humoral growth factor, as GLP-2 secreted from endocrine tumors or administered subcutaneously promotes small bowel growth (7). Accordingly, GLP-2 secreted from enteroendocrine cells in the large or small bowel may also potentially contribute to control of intestinal growth via the circulation through humoral mechanisms in a more classical endocrine pathway.

The majority of experiments studying the effects of peptide growth factors on intestinal epithelial proliferation have demonstrated an increased rate of crypt cell proliferation in association with growth factor activity (20). Comparatively few data exist regarding the effects of peptide growth factors on enterocyte apoptosis. Interleukin-11 administration after chemotherapy and radiotherapy in $\mathrm{C} 3 \mathrm{H} / \mathrm{HeJ}$ mice is associated with changes in both crypt cell proliferation and crypt cell (but not enterocyte) apoptosis (17). The cellular mechanism(s) underlying the actions of GLP-2 in modulating both crypt cell proliferation and enterocyte apoptosis as demonstrated here is not known. Future studies of the molecular effects of GLP-2 on cell proliferation and programmed cell death would be greatly facilitated by isolation and characterization of the GLP-2 receptor, a molecule that has not as yet been identified.

Few data are available regarding changes in the pattern of intestinal epithelial proliferation (and increased epithelial mass) that occur after withdrawal of intestinal growth factors such as growth hormone 
(GH), EGF, or IGF-I. Consequently, it is not clear whether the increased intestinal mass that develops as a consequence of growth factor treatment regresses rapidly or persists for longer periods of time. The rapid turnover of the intestinal epithelium suggests that withdrawal of growth factors may indeed be associated with rapid changes in the rate of crypt cell proliferation, leading to a reduction in the mass of the intestinal epithelium. The regression of the GLP-2-induced increase in small intestinal epithelial (mucosal) thickness by 10 days after cessation of GLP-2 is consistent with an ongoing requirement for increased levels of GLP-2 for maintenance of increased villus epithelium. After withdrawal of GLP-2, the programmed balance of intestinal epithelial proliferation and enterocyte programmed cell death likely reverts toward values in nontreated mice, leading to normalization of small bowel villus height and bowel weight. Interestingly, the enterocyte life span in the small intestines of 24-mo-old C57BL mice was observed to be modestly increased compared with the rates in younger 6- to 7-mo-old animals (9), consistent with our finding that the regression of villus height toward normal after cessation of GLP-2 was not yet complete 10 days after cessation of GLP-2 treatment in older mice.

The factors that regulate small bowel growth are complex and include luminal nutrients, polyamines, and both humoral and luminal growth factors $(5,6,19$, 26). We have now shown that GLP-2 increases growth of the small bowel villus epithelium in a gender- and age-independent manner. The compensatory bowel hyperplasia that develops despite reduced oral intake suggests that humoral factors independent of luminal nutrition may be important for small bowel adaptation and growth (26). As the intestinal PGDP GLP-1 has recently been shown to modulate food intake and satiety $(23,28)$, one potential explanation for the growth-promoting effects of GLP-2 may simply be an effect of this peptide on increasing food intake, thereby leading to increased intestinal epithelial proliferation. In contrast to the inhibitory effects of intracerebroventricular GLP-1 on food intake, GLP-2 administered subcutaneously for 9 days had no effect on food consumption, suggesting that its effects as a small bowel growth factor are independent of any putative change in nutrient intake.

A number of peptide hormones have been shown to function as regulators of intestinal epithelial proliferation, including neurotensin $(15,33)$. Intriguingly, neurotensin administration in the rat small bowel resection model was associated with a statistically significant increase in circulating levels of plasma enteroglucagon (4). The delineation of the intestinotrophic properties of GLP-2 raises the possibility that the effects of neurotensin on small bowel growth may be mediated in part through stimulation of GLP-2 secretion (4). Whether peptide growth factors trophic for the gut, such as EGF $(19,22)$, TGF- $\alpha(19,20)$, or IGF-I, stimulate the synthesis and/or release of GLP-2 remains to be determined.

Several lines of experimental evidence also support an important role for GH and IGF-I in the regulation of intestinal growth $(29,32)$. The majority of experiments using GH, IGF-I, and various peptide growth factors (20) generally involve short-term growth factor administration, either by continuous infusion or subcutaneous injection for 5-14 days. IGF-I, des(1-3)IGF-I, and LR ${ }^{3}$ IGF-I administered to rats for 7 days all led to increased mass of the stomach and both small and large bowel growth in catabolic dexamethasone-treated rats (21). Increased mass, protein, and DNA content were also observed in the muscularis layer of IGF-I-treated rats (21), suggesting that, in contrast to GLP-2, the growth-promoting effects of IGF-I in the intestine are not epithelial specific. Continuous administration of IGF-I or the IGF-I analog LR ${ }^{3}$ IGF-I to female rats for longer periods of time (14 days) was also associated with an increase in total gut weight, small bowel weight, and small bowel length (24).

In contrast to the results of short-term studies, few experiments have examined the effects of longer-term growth factor administration on bowel growth in vivo. Recombinant human EGF administered subcutaneously to 7 - to 8 -wk-old male Wistar rats for $4 \mathrm{wk}$ produced an increase in the mass of the small bowel that was largcly attributable to an increase in intestinal mucosal epithelium (30). Although we initially demonstrated that short-term (10-14 days) administration of GLP-2 consistently produces a 1.5- to 2 -fold increment in the weight of the mouse small intestine (7), the data presented here extend these observations by demonstrating that daily GLP-2 administration for up to $3 \mathrm{mo}$ is associated with a statistically significant increase in small bowel mass and crypt-plus-villus height. Furthermore, the intestinotrophic effects of GLP-2 were detected in both male and female mice of various ages and in very young and older rodents. The rapid turnover of the intestinal epithelium may potentially explain the lack of desensitization (and sustained efficacy of GLP-2) observed in the experiments involving daily administration of GLP-2 for $3 \mathrm{mo}$.

The molecular forms and circulating levels of GLP-2 in animals or human subjects have not been extensively studied. Analysis of the circulating levels of GLP-2 in human plasma by radioimmunoassay demonstrated fasting levels of $151 \pm 14 \mathrm{pmol} / \mathrm{l}$, which rose to $225 \pm 15 \mathrm{pmol} / \mathrm{l} 2 \mathrm{~h}$ after a mixed meal (18). A recent study demonstrated that short-term $(4 \mathrm{~h})$ infusion of GLP-2 intravenously in rats increased the transport rate of D-glucose, suggesting that the growth-promoting effects of GLP-2 may be associated with rapid changes in substrate transport in vivo (3). Whether basal levels of GLP-2 are important for nutrient absorption, small bowel epithelial growth, or for the small bowel adaptive response to injury cannot be inferred from the present studies. Furthermore, no human or animal models of GLP-2 deficiency are currently available for analysis. Nevertheless, the data presented here are clearly consistent with a role for GLP-2 in the control of small bowel growth and/or adaptation. Intriguingly, we also detected an increase in the protein content of the large bowel after GLP-2 administration; hence, the effect (whether direct or indirect) of GLP-2 
on the intestine appears not to be restricted to the small bowel. Taken together with the known distribution of GLP-2-containing enteroendocrine cells in the large bowel, these observations suggest that further studies of the mechanisms underlying the intestinotrophic properties of GLP-2 in both the small and large bowel are clearly warranted.

We thank Kelvin So, Susanna Tjian, and Aida Stefan for technical assistance.

This work was supported in part by an operating grant from the National Science and Engineering Research Council of Canada and Allelix Biopharmaceuticals. D. J. Drucker is a consultant to Allelix Biopharmaceuticals.

Address for reprint requests: D. .J. Drucker, The Toronto Hospital, 200 Elizabeth St. CCRW3-838, Toronto, ON, Canada M5G 2C4.

Received 17 September 1996; accepted in final form 14 February 1997.

\section{REFERENCES}

1. Behringer, R. E., T. M. Lewin, C. J. Quaife, R. D. Palmiter, R. L. Brinster, and A. J. D'Ercole. Expression of insulin-like growth factor I stimulates normal somatic growth in growth hormone-deficient transgenic mice. Endocrinology 127: 10331040, 1990.

2. Byrne, T. A., T. B. Morrissey, T. V. Nattakom, T. R. Ziegler, and D. W. Wilmore. Growth hormone, glutamine and a modified diet enhance nutrient absorption in patients with severe short bowel syndrome. J. Parenter. Enteral Nutr. 19: 296-302, 1995.

3. Cheeseman, C. I., and R. Tsang. The effect of gastric inhibitory polypeptide and glucagon-like peptides on intestinal hexose transport. Am. J. Physiol. 271 (Gastrointest. Liver Physiol. 34): G477-G482, 1996.

4. De Miguel, E., I. A. Gomez De Segura, H. Bonet, J. A. Rodriguez Montes, and A. Mata. Trophic effects of neuroten$\sin$ in massive bowel resection in the rat. Dig. Dis. Sci. 39: 59-64, 1994.

5. Dowling, R. H. Small bowel adaptation and its regulation. Scand. J. Gastroenterol. 17: 53-74, 1982.

6. Dowling, R. H. Cellular and molecular basis of intestinal and pancreatic adaptation. Scand. J. Gastroenterol. 193, Suppl. 27: 64-67, 1992.

7. Drucker, D. J., P. Ehrlich, S. L. Asa, and P. L. Brubaker. Induction of intestinal epithelial proliferation by glucagon-like peptide 2. Proc. Natl. Acad. Sci. USA 93: 7911-7916, 1996.

8. Evers, B. M., M. Izukura, S. Rajaraman, D. Parekh, K. Thakore, K. Yoshinaga, T. Uchida, C. M. Townsend, Jr., and J. C. Thompson. Effect of aging on neurotensin-stimulated growth of rat small intestine. Am. J. Physiol. 267 (Gastrointest. Liver Physiol. 30): G180-G186, 1994.

9. Ferraris, R. P., and R. R. Vinnakota. The time course of adaptation of intestinal nutrient uptake in mice is independent of age. J. Nutr. 125: 2172-2182, 1995.

10. Fuller, P. J., D. J. Beveridge, and R. G. Taylor. Ileal proglucagon gene expression in the rat: characterization in intestinal adaptation using in situ hybridization. Gastroenterology 104: 459 466, 1993.

11. Gleeson, M. H., S. R. Bloom, J. M. Polak, K. Henry, and R. H. Dowling. Endocrine tumour in kidney affecting small bowel structure, motility, and absorptive function. Gut 12: 773-782, 1971.

12. Goodlad, R. A., W. Lenton, M. A. Ghatei, T. E. Adrian, S. R. Bloom, and N. A. Wright. Effects of an elemental diet, inert bulk and different types of dietary fibre on the response of the intestinal epithelium to refeeding in the rat and relationship to plasma gastrin, enteroglucagon, and PYY concentrations. Gut 28: 171-180, 1987.

13. Gregor, M., A. Stallmach, H. Menge, and E. O. Riecken. The role of gut glucagon-like immunoreactants in the control of gastrointestinal cpithelial cell renewal. Digestion 46: 59-65, 1990.

14. Howard, L., M. Ament, C. R. Fleming, M. Shike, and E. Steiger. Current use and clinical outcome of home parenteral and enteral nutrition therapies in the United States. Gastroenterology 109: 355-365, 1995.

15. Izukura, M., B. M. Evers, D. Parekh, K. Yoshinaga, T. Uchida, C. M. Townsend, Jr., and J. C. Thompson. Neurotensin augments intestinal regeneration after small bowel resection in rats. Ann. Surg. 215: 520-527, 1992.

16. Jones, J. I., and D. R. Clemmons. Insulin-like growth factors and their binding proteins: biological actions. Endocr. Rev. 16: 3-34, 1995.

17. Orazi, A., X. Du, Z. Yang, M. Kashai, and D. A. Williams. Interleukin-11 prevents apoptosis and accelerates recovery of small intestinal mucosa in mice treated with combined chemotherapy and radiation. Lab. Invest. 75: 33-42, 1996.

18. Orskov, C., and J. J. Holst. Radio-immunoassays for glucagonlike peptides 1 and 2 (GLP-1 and GLP-2). Scand. J. Clin. Lab. Invest. 47: 165-174, 1987.

19. Podolsky, D. K. Regulation of intestinal epithelial proliferation: a few answers, many questions. Am. J. Physiol. 264 (Gastrointest. Liver Physiol. 27): G179-G186, 1993.

20. Potten, C. S., G. Owen, D. Hewitt, C. A. Chadwick, H. Hendry, B. I. Lord, and L. B. Woolford. Stimulation and inhibition of proliferation in the small intestinal crypts of the mouse after in vivo administration of growth factors. Gut 36: 864-873, 1995.

21. Read, L. C., F. M. Tomas, G. S. Howarth, A. A. Martin, K. J. Edson, C. M. Gillespie, P. C. Owens, and F. J. Ballard. Insulin-like growth factor-I and its N-terminal modified analogues induce marked gut growth in dexamthasone-treated rats. J. Endocrinol. 133: 421-431, 1992.

22. Saxena, S. K., J. S. Thompson, and J. G. Sharp. Role of epidermal growth factor in intestinal regeneration. Surgery 111: 318-325, 1992.

23. Scrocchi, L. A., T. J. Brown, N. Maclusky, P. L. Brubaker, A. B. Auerbach, A. L. Joyner, and D. J. Drucker. Glucose intolerance but normal satiety in mice with a null mutation in the glucagon-like peptide receptor gene. Nat. Med. 2: 1254-1258, 1996.

24. Steeb, C.-B., J. F. Trahair, F. M. Tomas, and L. C. Read. Prolonged administration of IGF peptides enhances growth of gastrointestinal tissues in normal rats. Am. J. Physiol. 266 (Gastrointest. Liver Physiol. 29): G1090-G1098, 1994.

25. Stevens, F. M., R. W. Flanagan, D. O'Gorman, and K. D. Buchanan. Glucagonoma syndrome demonstrating giant duodenal villi. Gut 25: 784-791, 1984.

26. Taylor, R. G., and P. J. Fuller. Humoral regulation of intestinal adaptation. Baillieres Clin. Endocrinol. Metab. 8: 165-183, 1994.

27. Taylor, R. G., K. Verity, and P. J. Fuller. Ileal glucagon gene expression: ontogeny and response to massive small bowel resection. Gastroenterology 99: 724-729, 1990.

28. Turton, M. D., D. O'Shea, I. Gunn, S. A. Beak, C. M. B. Edwards, K. Meeran, S. J. Choi, G. M. Taylor, M. M. Heath, P. D. Lambert, J. P. H. Wilding, D. M. Smith, M. A. Ghatei, J. Herbert, and S. R. Bloom. A role for glucagon-like peptide-1 in the central regulation of feeding. Nature 379: 69-72, 1996.

29. Ulshen, M. H., R. H. Dowling, C. R. Fuller, E. M. Zimmerman, and P. K. Lund. Enhanced growth of small bowel in transgenic micc overexpressing bovine growth hormone. Gastroenterology 104: 973-980, 1993.

30. Vinter-Jensen, L., M. Smerup, P. Kissmeyer-Nielsen, and S. S. Posulsen. Chronic systemic treatment with epidermal growth factor in the rat increases the mucosal surface of the small intestines. Regul. Pept. 60: 117-124, 1995.

31. Ward, A., B. Bates, R. Fisher, L. Richardson, and C. F. Graham. Disproportionate growth in mice with IGF-2 transgenes. Proc. Nall. Acad. Sci. USA 91: 10365-10369, 1994.

32. Winesett, D. E., M. H. Ulshen, E. C. Hoyt, N. K. Mohapatra, C. R. Fuller, and P. K. Lund. Regulation and localization of the insulin-like growth factor system in small bowel during altered nutrient status. Am. J. Physiol. 268 (Gastrointest. Liver Physiol. 31): G631-G640, 1995

33. Wood, J. G., H. D. Hoang, L. J. Bussjaeger, and T. E. Solomon. Neurotensin stimulates growth of small intestine in rats. Am. J. Physiol. 255 (Gastrointest. Liver Physiol. 18): G813-G817, 1988. 